\title{
The Newcastle Pediatric Mitochondrial Disease Scale: translation and cultural adaptation for use in Brazil
}

\author{
Escala Pediátrica de Doença Mitocondrial de Newcastle: tradução e adaptação cultural \\ para uso no Brasil \\ Gabriela Palhares Campolina-Sampaio', Laura Maria de Lima Belizário Facury Lasmar², Beatriz Silva Vilela \\ Ribeiro ${ }^{3}$, Juliana Gurgel-Giannetti²
}

\begin{abstract}
Objective: The aim of this study was to translate and adapt the Newcastle Paediatric Mitochondrial Disease Scale (NPMDS) to Portuguese for use in Brazil. Methods: The scale was applied in 20 pediatric patients with mitochondrial disease, in three groups: myopathy $(n=4)$; Leigh syndrome $(n=8)$; and encephalomyopathy $(n=8)$. Scores were obtained for the various dimensions of the NPMDS, and comparisons were drawn between the groups. Results: There was a statistically significant difference between the myopathy group and the Leigh syndrome group ( $p=0.0085$ ), as well as between the myopathy and encephalomyopathy groups $(p=0.01)$. Conclusions: The translation of the NPMDS, and its adaptation to the socioeconomic and cultural conditions in Brazil, make the NPMDS score useful as an additional parameter in the evaluation and monitoring of pediatric patients with MD in Brazil.
\end{abstract}

Keywords: Newcastle disease; mitochondrial diseases, mitochondrial myopathies; mitochondrial encephalomyopathies; Leigh disease.

\section{RESUMO}

Objetivo: 0 objetivo do presente estudo foi realizar a tradução e adaptação da escala NPMDS para a população brasileira. Métodos: A escala foi aplicada em 20 crianças e adolescentes com doença mitocondrial (DM) divididos em três grupos: miopatia ( $n=4$ ), síndrome de Leigh $(n=8)$ e encefalomiopatia $(n=8)$. Obteve-se os escores separados das dimensões da escala NPMDS, foram realizadas comparações entre os escores da NPMDS nos diferentes grupos. Conclusão: A tradução da escala NPMDS e sua adequação as condições socioeconômicas e culturais de nossa população tornam este instrumento um parâmetro adicional na avaliação e acompanhamento de pacientes pediátricos com DM.

Palavras-chave: doença de Newcastle; doenças mitocondriais; miopatias mitocondriais; encefalomiopatias mitocondriais; doença de Leigh.

Mitochondrial diseases are characterized by defects in respiratory chain function due to mutations in mitochondrial or nuclear DNA. Consequently, the pattern of inheritance can be Mendelian (autosomal recessive, autosomal dominant, or X-linked) or strictly maternal ${ }^{1,2,3,4,5}$. Mutations in nuclear DNA are seen in the majority $(80 \%)$ of pediatric patients with mitochondrial diseases, which is not the case among their adult counterparts ${ }^{1,2,3,4,5}$.

Because mitochondria are present in all human tissue types, mitochondrial diseases are multisystemic in character. Among the most frequently affected organs are the nervous system (central and peripheral), musculoskeletal system, heart, kidneys, and liver ${ }^{6,7,8}$. In pediatric patients, the phenotypes are more severe and are usually multisystemic (often involving the central nervous system), only rarely presenting as isolated myopathy ${ }^{9}$.

The incidence of mitochondrial disease is estimated to be at least 1/3500-5000 in a population. Therefore, in addition to their phenotypic/genetic heterogeneity and multisystemic character, mitochondrial diseases can be

${ }^{1}$ Universidade Federal de Minas Gerais, Faculdade de Medicina, Fisioterapeuta do Ambulatório de Doenças Neuromusculares HC/UFMG, Belo Horizonte MG, Brasil;

${ }^{2}$ Universidade Federal de Minas Gerais, Faculdade de Medicina, Departamento de Pediatria, Belo Horizonte MG, Brasil;

${ }^{3}$ Universidade Federal de Minas Gerais, Hospital das Clínicas, Serviço de Neuropediatra, Belo Horizonte MG, Brasil;

Correspondence: Juliana Gurgel Giannetti; Universidade Federal de Minas Gerais, Faculdade de Medicina; Av. Prof. Alfredo Balena, 190; $30130-100$ Belo Horizonte MG, Brasil; E-mail: gurgelju@yahoo.com.br

Conflict of interest: There is no conflict of interest to declare.

Received 19 December 2015; Accepted 13 June 2016. 
considered to have a high incidence, with high rates of morbidity and mortality ${ }^{1,2}$. The recognition of these diseases is of great importance because it allows clinicians to predict potential complications, as well as to define the treatment and prognosis of the affected patients.

Because mitochondrial diseases present with great variability in their clinical course, it is of outmost importance to understand and monitor their progression so that clinicians can guide and direct the patient, with the aim of optimizing care and preserving or improving quality of life. There is a real need for a reliable tool that will allow better monitoring of patients. To date, only one scale has been developed for the clinical follow-up and quality-of-life assessment of children and adolescents with mitochondrial disorders: the Newcastle Paediatric Mitochondrial Disease Scale (NPMDS) ${ }^{10}$, which was developed and validated in 2006 by the Mitochondrial Research Group of Newcastle University, in Newcastle upon Tyne, UK, considered to be an international referral center for the study of mitochondrial diseases.

In Brazil, there are, as yet, no clinical evaluation scales that have been validated for use in monitoring patients with mitochondrial diseases. Therefore, the aim of this study was to validate the NPMDS for use in Brazil and apply it in a sample of the Brazilian population. It is a reliable instrument with good reproducibility, where variation can be tracked over the course of the disease providing important information on the clinical course and quality of life of patients, resulting in a better approach to the treatment of these patients.

\section{METHODS}

\section{Study site}

This was a cross-sectional study conducted at the outpatient clinic for neurogenetic diseases of the Universidade Federal de Minas Gerais Hospital das Clinicas. The Clinic is a referral center for mitochondrial disease in the state of Minas Gerais and is staffed by a multidisciplinary team.

\section{Study criteria}

Participants were recruited from among the patients enrolled at the outpatient clinic. The inclusion criteria were: being $\leq 18$ years of age and having been diagnosed with mitochondrial disease by a pediatric neurologist, through muscle biopsy (with histochemical or molecular studies) and neuroradiological imaging (in accordance with the criteria set forth by the North American Mitochondrial Disease Consortium-unpublished data) and by Bernier et al. ${ }^{11}$ and by Morava et al. ${ }^{12}$. We selected 20 patients who met the criteria for inclusion: four with myopathy; eight with Leigh syndrome; and eight with encephalomyopathy.

\section{The NPMDS}

The NPMDS is subdivided by patient age ( $0-24$ months, 2-11 years, and 12-18 years) and comprises four domains: Section I: Current Function (evaluates communication, feeding, vision, hearing, self-care, mobility, and level of education); Section II: System Specific Involvement (evaluates neurological, endocrinological, gastrointestinal, respiratory, cardiovascular, renal, hepatic, and hematological manifestations); Section III: Current Clinical Assessment (evaluates psychomotor development, vision, myopathy, ataxia, pyramidal/extrapyramidal system function, and neuropathy); and Section IV: Quality of Life (as assessed by the patients, when possible, or by their caregivers). The NPMDS is scored by section (domain), and the final (total) score is the sum of all section scores. The section scores vary by age group. For section I, the maximum score is 15 for the 0-24 months group and 24 for the other two age groups (2-11 years and 12-18 years). For section II, the maximum score is 27 for the 0-24 months group and 30 for the other two age groups. For section III, the maximum score is 28 for the $0-24$ months group and 31 for the other two age groups. For section IV, the maximum score is 25, regardless of age group. Therefore, the maximum possible total NPMDS scores are 95 for subjects under 24 months of age and 107 for those between two and 18 years of age. Higher scores indicate worse conditions ${ }^{10}$.

\section{Procedures}

\section{Translation and adaptation of the NPMDS}

The original version of the NPMDS was kindly provided by Drs. Robert McFarland and Doug Turnbull, of Newcastle University, the lead researchers of the Mitochondrial Research Group that created and validated the scale. They also gave us permission to translate the NPMDS into Portuguese. To translate the instrument, we followed the Principles of Good Practice established by the International Society for Pharmacoeconomics and Outcomes Research Task Force for Translation and Cultural Adaptation ${ }^{13}$, step by step: preparation, forward translation, reconciliation, back translation, revision of the back translation, harmonization, pilot testing, review of the results of the pilot study, editing for spelling and syntax, and final reporting.

Two separate forward translations (from English to Portuguese) of the NPMDS were created, one by each of two Brazilian researchers (one physical therapist and one pediatric neurologist), working independently. A third Brazilian researcher subsequently created a single translation based on those first two versions. We commissioned American Journal Experts to do the back translation, which was then sent to Drs. McFarland and Turnbull, who checked it and suggested minor alterations. Those alterations were applied to the Portuguese-language version of the scale, which was then administered to the selected patients. 


\section{Statistical analysis}

We evaluated a non-probabilistic sample of 20 patients who met the inclusion criteria. The data collected were transferred to a database and processed. To compare means, medians and frequencies, we used Student's t-tests, chi-square tests, or Mann-Whitney tests, as indicated. To analyze correlations among the NPMDS section scores, we used Pearson's or Spearman's correlation coefficient, or both, depending on the distribution of the data. The level of statistical significance was set at $\mathrm{p}<0.05$.

\section{Ethical aspects}

The study was approved by the Research Ethics Committee of the Universidade Federal de Minas Gerais. All patients or their legal guardians gave written informed consent.

\section{RESULTS}

The distribution of the patients in the sample by diagnosis was four patients with mitochondrial myopathy, eight with Leigh syndrome and eight with encephalomyopathy. The mean age of the patients was $11.6 \pm 4.7$ years (range, 3-18 years). Of the 20 patients evaluated, 12 (60\%) were female.

Table 1 shows the mean NPMDS scores (domain scores and total scores) for the sample as a whole. Table 2 depicts

Table 1. Newcastle Pediatric Mitochondrial Disease Scale scores among pediatric patients $(n=20)$.

\begin{tabular}{|c|c|c|}
\hline NPMDS score & Mean \pm SD & Median (range) \\
\hline Section I (Current function) & $9.4 \pm 5.7$ & $9.5(1.0-21.0)$ \\
\hline $\begin{array}{l}\text { Section II (System specific } \\
\text { involvement) }\end{array}$ & $3.8 \pm 4.1$ & $2.0(0.0-13.0)$ \\
\hline $\begin{array}{l}\text { Section III (Current clinical } \\
\text { assessment)* }\end{array}$ & $13.6 \pm 6.4$ & $12.0(4.0-25.0)$ \\
\hline Section IV (Quality of life) & $10.9 \pm 4.4$ & $10.0(3.9-19.6)$ \\
\hline Total & $36.8 \pm 14.9$ & $35.9(9.9-64.9)$ \\
\hline
\end{tabular}

NPMDS: Newcastle paediatric mitochondrial disease scale; SD: standard deviation; Section I: Current Function domain; Section II: System Specific Involvement domain; Section III: Current Clinical Assessment domain; Section IV: Quality of Life domain. *One patient was excluded.

Table 2. Correlation between the mean total Newcastle Paediatric Mitochondrial Disease Scale score and the mean score for its Quality of Life domain, in a sample of pediatric patients $(n=20)$.

\begin{tabular}{lcl}
\hline Variable & $r^{* \star}$ & $p^{* *}$ \\
\hline NPMDS Quality of Life* domain score & 0.197 & 0.4 \\
\hline
\end{tabular}

NPMDS: Newcastle paediatric mitochondrial disease scale. *Assessed by the patients, when possible, or by their caregivers. ${ }^{*}$ Versus the total NPMDS score. the correlation between the mean total NPMDS score and the mean score for the NPMDS Quality of Life domain. A comparative analysis of the different diagnoses (myopathy, Leigh syndrome, and encephalomyopathy), by NPMDS score, is shown in Table 3. In terms of the median total NPMDS score, there was a statistically significant difference between the myopathy group and the Leigh syndrome group ( $p=0.0085)$, as well as between the myopathy and encephalomyopathy groups ( $p=0.01$ ). The difference between the Leigh syndrome group and the encephalomyopathy group was not statistically significant $(\mathrm{p}=0.63)$.

Table 4 shows the comparison of the myopathy, Leigh syndrome, and encephalomyopathy groups, in terms of quality of life. We found no significant difference among the three groups in relation to the median score for the NPMDS Quality of Life domain.

\section{DISCUSSION}

The NPMDS was created and validated to follow the natural history of mitochondrial disease, in order to have an instrument that can measure the progression of the disease in a given patient over time. The scale has been shown to have high inter-examiner reliability ${ }^{10}$. In the present study, the sample size was identical to that evaluated in the original

Table 3. Comparative analysis of the three different diagnoses, by total Newcastle Paediatric Mitochondrial Disease Scale score, in pediatric patients $(n=20)$.

\begin{tabular}{lcc}
\hline \multirow{2}{*}{ Disease form } & Total NPMDS score & $\mathrm{p}$ \\
\cline { 2 - 2 } & Median (range) & \\
\hline Myopathy & $15.4(9.0-25.0)$ & $0.0085^{\star}$ \\
\hline Leigh syndrome & $40.8(31.5-64.9)$ & $0.01 * \star$ \\
\hline Encephalomyopathy & $37.1(22.5-54.6)$ & $0.63 * \star \star$ \\
\hline
\end{tabular}

NPMDS: Newcastle paediatric mitochondrial disease scale. *Versus Leigh syndrome. ${ }^{* \star}$ Versus myopathy and encephalomyopathy. ${ }^{\star \star} V$ Versus Leigh syndrome.

Table 4. Comparative analysis of the three different diagnoses, by score on the Quality of Life domain of the Newcastle Paediatric Mitochondrial Disease Scale, in pediatric patients $(n=20)$.

\begin{tabular}{lcc}
\hline \multirow{2}{*}{ Disease form } & \multicolumn{1}{c}{ NPMDS QoL score } & P \\
\cline { 2 - 2 } & Median (range) & \\
\hline Myopathy & $5.9(3.9-12.4)$ & $0.05^{\star}$ \\
Leigh syndrome & $11.4(7.5-17.0)$ & $0.83^{\star \star}$ \\
Encephalomyopathy & $11.1(5.4-19.6)$ & 1.11 *** \\
\hline
\end{tabular}

NPMDS: Newcastle paediatric mitochondrial disease scale; QoL: Quality of life (domain). ${ }^{*}$ Versus Leigh syndrome. ${ }^{\star \star} V$ Versus myopathy and encephalomyopathy. ${ }^{* \star \star}$ Versus Leigh syndrome. 
NPMDS validation study ${ }^{10}$. As in that original study, our sample included no patients under two years of age. One possible explanation for this is that mitochondrial diseases are difficult to diagnose, as well as being more severe, in neonates and infants.

In our sample as a whole, the mean score for NPMDS section II (the System Specific Involvement domain) was lower than were those for section I (the Current Function domain) and section III (the Current Clinical Assessment domain), the last two being comparable with each other as well as being similar to the mean score for section IV (the Quality of Life domain). The low score for section II can be explained by the high number of patients with Leigh syndrome or encephalomyopathy who typically present with greater neurologic involvement and less involvement of other systems. The similarity between the section III and section I scores also reflects the neurological impairment and resulting functional impairment, respectively, observed in patients with Leigh syndrome or encephalomyopathy.

Considering the different forms of mitochondrial disease evaluated in this study, we looked for correlations between the total NPMDS score and the form of mitochondrial disease. The patients with myopathy had the best scores (i.e., a milder clinical presentation); the difference between the myopathy group and the Leigh syndrome group being statistically significant, as was that between the myopathy group and the encephalomyopathy group. However, there was no statistically significant difference between the Leigh syndrome and encephalomyopathy groups, which was expected as both forms are associated with a more severe clinical presentation, especially with regard to neurological impairment.

Using the Newcastle Mitochondrial Disease Adult Scale (NMDAS), Grady et al. ${ }^{14}$ evaluated 87 adult patients with single, large-scale mitochondrial DNA deletions. Those authors found that COX-deficient fiber density and age at symptom onset correlated with disease progression. They strongly recommended the use of the NMDAS in the evaluation of patients with mitochondrial disease. In addition to the periodic monitoring of the clinical status of patients, the NMDAS has also been used in studies evaluating treatments in adult patients with various forms of mitochondrial disease $\mathrm{e}^{15,16,17}$.

The NMDAS and NPMDS both not only allow the clinical status of mitochondrial disease patients to be evaluated over time but also facilitate the assessment of the patients' quality of life. Orsucci et al. ${ }^{18}$ evaluated the relationship between quality of life and disease progression in adult patients with mitochondrial myopathy. The authors applied the NMDAS, the Medical Outcomes Study 36-item Short-Form Health Survey (SF-36), and the manual muscle test of the Medical Research Council Scale. They demonstrated that the SF-36 score presented an inverse correlation with the NMDAS score, greater mitochondrial disease severity (higher NMDAS scores) translating to poorer quality of life (lower SF-36 scores). The importance of evaluating the quality of life in adult patients with mitochondrial disease led to the creation and validation of a scale specific for such patients, which has been shown to be a valid, consistent tool with good reproducibility ${ }^{19}$. In a systematic review of the impact of mitochondrial disease in pediatric patients and its impact on quality of parental life, Sofou ${ }^{20}$ found that the burden of stress, anxiety, and depression was higher among parents of children with mitochondrial disorders than among those of children with other metabolic disorders, resulting in poorer quality of life and social function for the parents and families of the children with mitochondrial disorders.

In the present study, we found no statistically significant differences among the three forms of mitochondrial disease (myopathy, Leigh syndrome, and encephalomyopathy), in terms of quality of life. Our finding that quality of life was slightly better among the patients in the myopathy group than among those in the Leigh syndrome and encephalomyopathy groups was expected, because myopathy has a milder clinical presentation than do the two other forms of mitochondrial disease. However, that comparison was clearly impaired by the size of the sample, in which there were fewer patients with isolated myopathy than with Leigh syndrome or encephalomyopathy, which could have influenced the result.

One study evaluated quality of life in the mothers of children with mitochondrial disease, in comparison with that determined for the mothers of children with intractable epilepsy (without mitochondrial disease) ${ }^{21}$. The authors observed that the women in the former group had a poorer quality of life and felt more overloaded, as well as showing higher levels of depression and anxiety-especially anxiety related to limitations, vitality, and health.

Our study has certain limitations, mainly related to the small size of the patient sample. However, the primary aim of the study was to translate and adapt the Portuguese-language version of the NPMDS for use in Brazil, and that goal was achieved. This translation and adaptation study lays the groundwork for the use of this scale in the monitoring and objective evaluation of the progression of mitochondrial diseases in our country.

In conclusion, the translation of the NPMDS and its adaptation to the socioeconomic and cultural conditions in Brazil, make the NPMDS score useful as an additional parameter in the evaluation and monitoring of pediatric patients with mitochondrial diseases. To our knowledge, there have been no studies employing such scales in pediatric patients with mitochondrial disease. The NPMDS could be used to evaluate potential treatments for the various forms of this disease. 
1. DiMauro S, Schon EA. Mitochondrial respiratory-chain diseases. N Engl J Med. 2003;348(26):2656-68. doi:10.1056/NEJMra022567

2. DiMauro S, Schon EA. Mitochondrial disorders in the nervous system. Annu. Rev Neurosci. 2008;31(1):91-123. doi:10.1146/annurev.neuro.30.051606.094302

3. Oskoui M, Davidzon G, Pascual J, Erazo R, Gurgel-Giannetti J, Krishna S et al. Clinical spectrum of mitochondrial DNA depletion due to mutations in the thymidine kinase (TK2) gene. Arch Neurol. 2006;63(8):1122-6. doi:10.1001/archneur.63.8.1122

4. Di Mauro S. Mitochondrial encephalomiopathies: fifth years on. Neurology. 2013;81:281-91. doi:10.1212/WNL.0b013e31829bfe89

5. Goldstein AC, Bhatia P, Vento JM. Mitochondrial disease in childhood: nuclear encoded. Neurotherapeutics. 2013;10(2):212-6. doi:10.1007/s13311-013-0185-6

6. Horvath R, Gorman G, Chinnery PF. How can we treat mitochondrial encephalomyopathies? Approaches to therapy. Neurotherapeutics. 2008;5(4):558-68. doi:10.1016/j.nurt.2008.07.002

7. Mandel H, Szargel R, Labay V, Elpeleg O, Saada A, Shalata A et al. The desoxyguanosine kinase gene is mutated in individuals with depleted hepatocerebral mitochondrial DNA. Nat Genet. 2001;29(3):337-41. doi:10.1038/ng746

8. Hirano M, Davidson M, DiMauro S. Mitochondria and the heart. Curr Opin Cardiol. 2001;16(3):201-10. doi:10.1097/00001573-200105000-00008

9. Ardissone A, Lamantea E, Invernizzi F, Zeviani M, Genitrini S, Moroni I et al. Mitochondrial diseases in childhood. Curr Mol Med. 2014;14(8):1069-78. doi:10.2174/1566524014666141010155317

10. Phoenix C, Schaefer AM, Elson JL, Morava E, Bugiani M, Uziel G et al. A scale to monitor progression and treatment of mitochondrial disease in children. Neuromuscul Disord. 2006;16(12):814-20. doi:10.1016/j.nmd.2006.08.006

11. Bernier FP, Bneh A, Dennett X, Chow CW, Cleary MA, Thorburn DR. Diagnostic criteria for respiratory chain disordres in adults and children. 2002;59(9):1406-11.
12. Morava E, Heuvel L, Hol F, Vries MC, Hogeveen M, Rodenburg RJ et al. Mitochondrial disease criteria: diagnostic applications in children. Neurology. 2006;67(10):1823-6. doi:10.1212/01.wnl.0000244435.27645.54

13. Wild D,Grove A, Martin M, Eremenco S, McElroy S, Verjee-Lorenz A et al. Principles of good practice for the translation and cultural adaptation process for patient-reported outcomes (PRO) measures: report of the ISPOR task force for translation and cultural adaptation. Value Health. 2005;8(2):94-104.

14. Grady JP, Campbell G, Ratnaike T, Blakely EL, Falkous G, Nesbitt $V$ et al. Disease progression in patients with single, large-scale mitochondrial DNA deletions. Brain. 2014;137(2):323-34.

15. Blankenberg FG, Kinsman SL, Cohen BH, Goris ML, Spicer KM, Perlman SL et al. Brain uptake of Tc99m-HMPAO correlates with clinical response to the novel redox modulating agent EPI-743 in patients with mitochondrial disease. Mol Genet Metab. 2012;107(4):690-9.

16. Saito K, Kimura N, Oda N, et al. Pyruvate therapy for mitochondrial DNA depletion syndrome. Biochim Biophys Acta. 2012;1820(5):632-6.

17. Fujii T, Nozaki F, Saito K, Hayashi A, Nishigaki Y, Murayama Ket al. Efficacy of pyruvate therapy in patients with mitochondrial disease: a semi-quantitative clinical evaluation study. Mol Genet Metab. 2014;112(2):133-8.

18. Orsucci D, Calsolaro V, Siciliano G, Mancuso M. Quality of life in adult patients with mitochondrial myopathy. Neuroepidemiology. 2012;38(3):194-5. doi:10.1159/000337161

19. Elson JL. Cadogan M, Apabhai S, Whittaker RG, Phillips A, Trennell MI et al. Initial development and validation of a mitochondrial disease quality of life scale. Neuromuscul Disord. 2013;23(4):324-9.

20. Sofou K. Mitochondrial disease: a challenge for the caregiver, the family, and society. J Child Neurol. 2013;28(5):663-7.

21. Kim KR, Lee E, Namkoong K, Lee YM, Lee JS, Kim HD. Caregiver's burden and quality of life in mitochondrial disease. Pediatr Neurol. 2010;42(4):271-6. 


\section{Erratum}

The Newcastle Pediatric Mitochondrial Disease Scale: translation and cultural adaptation for use in Brazil Arq Neuropsiquiatr 2016;74(11):909-913. DOI: http://dx.doi.org/10.1590/0004-282x20160137

The name of $4^{\text {th }}$ the author:

Juliana Gurgel Giannetti

\section{Should be:}

Juliana Gurgel-Giannetti 